\title{
The Empirical Study on Impact of Consumer Experience to Consumer Loyalty of Coffee Chain in Guangzhou
}

\author{
JING BAI \\ School of Business Administration, \\ South China University of Technology \\ Guangzhou, China \\ bmzcliu@ scut.edu.cn
}

\author{
LU JIANG \\ School of Business Administration, \\ South China University of Technology \\ Guangzhou, China \\ jianglu081032@126.com
}

\begin{abstract}
The purpose of this paper is to study on the impact of consumers' experience to their loyalty in the city of Guangzhou. Based on the related literature study, it has been built the concept model of causal relationship among experiential medium, experiential value and consumer loyalty. We use the empirical study to analyze the model by statistical analysis with SPSS16.0. In this paper, a total of 9 hypothesizes are brought forward. 240 questionnaires are sent out and 202 valid questionnaires are received. Our results indicate that the coffee shop's environment affects the functional value, emotional value and social value positively, and personal service has a significant impact on functional value and affective value. Emotional value and social value also have a significant impact on consumer loyalty but functional value does not have a direct impact on loyalty. However, different individual characteristics have a significant impact on consumer loyalty. The results suggest that competitive advantages can be achieved from Brand-building and themeshaping experience.
\end{abstract} Chain

Keywords-Experience; Experiential Value; Loyalty; Coffee

\section{INTRODUCTION}

Norris (1941) was one of the first scholars who had put forward the consumer experience, and he stressed that the emphasis of the consumer experience was service rather than the article itself. Lebergott(1993) brought forward that the purpose of economic activity was not the output itself, but the experience via consumption. However, in recent years, scholars' study can be broadly classified as the following: 1 . Experience with consumer behavior. Barlow \& Maul (2000) indicated that, in the experience economy era, business consumers should enhance emotional value to improve the competitive advantage. 2. Brand experience. Drew Barrand (2004) thought that the interaction between consumer experience and consumer could create the brand personality and transmission of values. 3. Tourist experience. Hsin-You Chou (2002) selected the theme park for study and extracted five structural elements -Principal Benefits, Entertainment and Hospitality, Themes, Trillrides and Unique Facilities. 4. Learning experience. Elizebath \& Harlan (2004) concluded that it was necessary to create a more participatory, more interesting learning experience to make learning a more simple, effective and lasting memory.

However, the academic study of the coffee chain is only limited to Starbucks marketing research experience, so there is no theoretical study of experience of coffee marketing chain. Additionally, many of them remain in the use of marketing theories of knowledge and experience to analyze the characteristics of the coffee shop. Therefore, this study attempts to combine experiential marketing with consumer loyalty through empirical study to examine which type of experience has a significant impact on loyalty. The results will serve as a theoretical basis for marketing strategy of coffee chain enterprises so that they can start the practice of targeted marketing.

This paper is organized as follows. Firstly, we apply the theories of consumer Experience and Consumer Loyalty to develop a model examining the causal relationship of Experiential Medium, Experiential Value and Consumer Loyalty. Then, we test the model empirically by survey and objective data which is collected from consumers in coffee chains in Guangzhou. Finally, we discuss the empirical findings contributing to the theory and practice of consumer experience to consumer loyalty.

\section{THEORETICAL BACKGROUNDS AND HYPOTHESIS}

Schmitt (1999) defined experience as the response of individuals to the isolated incident. Schmitt (1999) proposed the concept of experiential marketing and defined that after observing or participating in events, consumers felt stimulation and had motivation, then this would result in consumer behavior or thinking identity. He concluded that structure of marketing experience included the following two aspects: Strategic Experiential Models (SEMs) and ExPros. Zeithaml (1988) pointed out that the value was derived from assessment of the results after consumers paying attention to difference between acquirement and payment. Also, as the first scholar putting forward the concept of consumer experience, Norris (1941) stressed the value of consumer goods was based on the experience provided. Besides, Wenjie Xiao (2003) pointed out 
that consumer loyalty was the most important whatever the type of an enterprise.

Based on the discussion in the preceding section, it proposes a conceptual model shown in Fig.1. The contention of the model is that consumer loyalty is MEDIUMted by the environment, service. Accordingly, we develop and test 9 hypotheses representing:

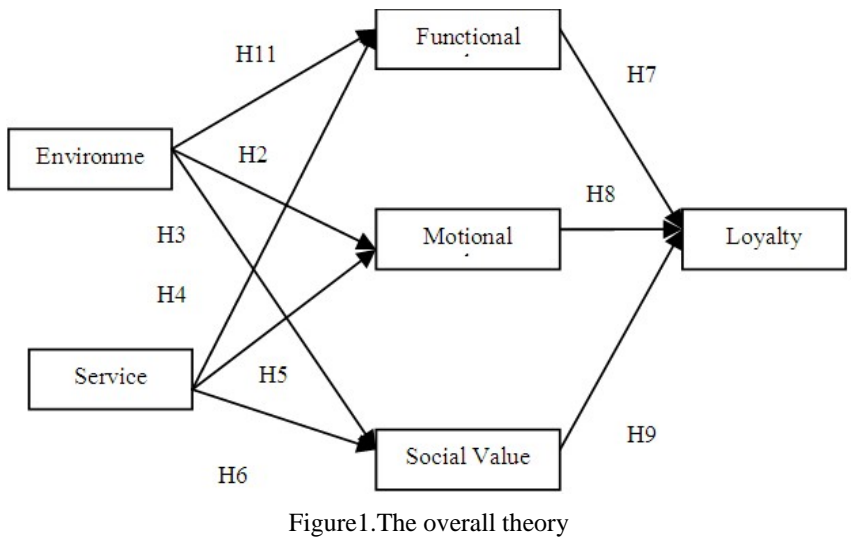

Consumer in coffee shops would be influenced by hearing, smelling, visual and sensory information. And this non-verbal information would furthermore stimulate consumption (Holbrook \& Hirschman, 1982). The space environment, such as light, decoration, decoration and colors, finally had a positive or negative impact on consumers. Belk (1988) suggested that consumers would get self-expression and positive existence from the products and services consuming. A good consuming environment would contribute to a better positive attitude towards commercial value for consumers. Furthermore, when consumers preferred to consumer environment, they would reduce the psychological cost, time spent, and then wished to raise further patronage (Baker et al., 2002). Lai Zheng-Hao (2004) took fitness center as an example and found that environment had played a significantly positive role in experiential value and the experiential environment MEDIUM had the most distinct impact on consumer experience value.

Therefore, aimed at testing impact of a coffee shop's environment on consumers' experience value, the following hypothesizes are set forth:

$\mathrm{H} 1$ : Environment has a positive impact on the functional value;

H2: Environment has a positive impact on the emotional value;

H3: Environment has a positive impact on the social value.

\section{A. Impact of Service on Experiential value}

The attitude of service would greatly affect the quality of coffee products and service quality perception of consumers (Binter, 1990). In other words, personnel services of shopping malls would have an effect on consumer's evaluation of service quality (Sasser, 1987; Bitner, 1990). In transmission of service quality, the greatest impact could be achieved by interaction with people (Biner et al., 1994). Cordial attitude of service and professional knowledge could finally contribute to a good relationship between consumers and sellers (Duncan and
Moriarty, 1997). Yuan Yi-Cheng (2003) conducted a survey in bookstores, Starbucks Coffee and IKEA, and got the conclusion that consumer sentiment had an impact on consumer satisfaction by emotional value and quality of service influenced consumer satisfaction through the functional value.

Therefore, based on the literature reference above, to test the relationship between service and experiential value, the following hypothesizes are set forth:

H4: Service has a positive impact on the functional value;

H5: Service has a positive impact on the emotional value;

H6: Service has a positive impact on the social value.

\section{B. Impact of Experiential value on Loyalty}

The consumer perception of experiential value would have a great effect on his act intention, and this would show the corresponding loyalty of an enterprise or its brand. Anderson \& Sullivan (1993) found that the extent of experiential value would have a positive impact on consumer re-purchase behaviors. And experiential value would affect the re-purchase behaviors in many ways, such as the re-purchase rate, word-ofmouth or loyalty (Yi, 1990). Wakefifeld \& Baker (1998) pointed out that the consumer perceived value and patronage intentions were relevant. Zheng Li-Jie's (2002) study indicated that consumer experiential value and extent of a post-shopping behavior were significantly related. Eun-Ju Lee \& Overby (2004) selected the consumer online shopping behavior for study, and found that the practical value and experiential value were both significantly positively correlated with satisfaction. Furthermore, they had a significant impact on consumer loyalty.

From the literature above can we see that experiential value has an significantly positive impact on consumer loyalty, but it still remains a mystery what the specific relationship between experiential value and loyalty is. So we set forth the following hypothesizes:

H7: Functional value has a positive impact on the loyalty;

H8: Emotional value has a positive impact on the loyalty;

H9: Social value has a positive impact on the loyalty.

\section{RESEARCH METHODOLOGY}

\section{A. Samples}

The sample of this study was mainly from the coffee chain's consumers in Guangzhou. We drew this sample by getting the data by interviewing the informants directly for investigation. The survey samples were taken from consumers in Starbucks, Banilla Coffee, SPR, Garden Café, RBT and UBC in Guangzhou(See Table 1).

TABLE I. SURVYE OBJECT

\begin{tabular}{|c|c|c|}
\hline $\begin{array}{c}\text { Name of Coffee } \\
\text { Shop }\end{array}$ & Chain Form & The number of stores \\
\hline Starbucks & Direct linkage & 30 \\
\hline Banilla Coffee & $\begin{array}{c}\text { Commissioned } \\
\text { to join }\end{array}$ & 11 \\
\hline
\end{tabular}




\begin{tabular}{|c|c|c|}
\hline SPR & $\begin{array}{c}\text { Commissioned } \\
\text { to join }\end{array}$ & 12 \\
\hline Garden Cafe & Direct linkage & 21 \\
\hline RBT & Direct linkage & 31 \\
\hline UBC & $\begin{array}{c}\text { Commissioned } \\
\text { to join }\end{array}$ & 18 \\
\hline
\end{tabular}

\section{B. Measures}

Our measures are shown as fellows: Environment (E), seven scale items which were used to measure it and the theoretical domain for the scale items was adapted from Wakefield and Baker (1998) and Schmitt (1999). Service (S), five scale items were developed for measuring it (Baker, Parasuraan, Grewal and Voss,2002). As for Functional Value (FV), Emotional Value (EV) and Social Value (SV), each had four scale items (Sweeney and Soutar, 2001). Also, three scale items were used for Loyalty (L) ( Gronholdt,Martesen \& Kristensen,2000; Ingrid, 2004)

\section{Method of Data Analysis}

The diagnostic tool of this analysis is SPSS16.0, which is a professional statistical software. The statistical analysis methods are as follows: Descriptive Statistical Analysis, Reliability Analysis, Validity Analysis, Correlation Analysis, Multiple Liner Regression Analysis.

\section{Data Collection}

Our sample consisted of 202 questionnaires. The share of the male invested was $48.5 \%$ while the female was $51.5 \%$. The distribution of ages of people investigated presented normal distribution. 21 to 30 accounted for $51.5 \%$, while 31 to 50 was $34.6 \%$. The informants with degree of bachelor accounted for $75.2 \%$, with degree of master $11.4 \%$, and $13.4 \%$ for the others. These all ensured certain authenticity and reliability of the survey.

\section{ANALYSIS AND RESULTS}

\section{A. Reliability Analysis}

We computed Coefficient Alpha to assess the scale reliability. The total reliability of the questionnaire is 0.887 and the Cronbach's Alpha of each variable in the questionnaire is above 0.7 according to the data analysis. Therefore, it can be considered to have relatively high reliability, which represents that it is possible to do an empirical study.

\section{B. Validity Analysis}

\section{1) Factor Analysis of Experience Medium}

\section{a) Environment}

There are 7 questions in measuring the experience of environment, and KMO value of the rating scale is 0.785 , which means the consequence is available for factor analysis. The approximate Chi-square is 314.383 from Bartlett Test of Sphericity test and it achieves a significant level, which represents that there exist common factors in correlation matrix of the accessible population.

b) Service
There are 5 questions in measuring the experience of the service, and the KMO value of the rating scale is 0.835 , which means the consequence is available for factor analysis. The approximate Chi-square is 379.137 from Bartlett's sphericity test and it is significant, which represents that there exists common factors in correlation matrix of the accessible population.

\section{2) Factor Analysis of Experience Value}

There 12 rating scale items in measuring the experience value and the KMO value of the rating scale is 0.835 , which means the consequence is available for factorial analysis. As a result of the factorial analysis, it can draw the conclusion that there are 3 factors, whose cumulative contribution of variance accountes to $69.562 \%$. Despite of the factor loading of question NO.23 below 0.5 , the factor loading of other items in the questionnaire is above 0.5 .

\section{3) Factor Analysis of Loyalty}

There 3 questions in measuring the experience of the loyalty, and the KMO value of the rating scale is $0.721(>0.7)$, which means the consequence is available for factor analysis. The approximate Chi-square is 214.786 from Bartlett's sphericity test and it is significant.

\section{Correlation Analysis}

1) Correlation Analysis between Experience Medium and Experience Value

According to Table II, environment and service are correlative to all the three dimensions of experience value. Correlation is significant at the 0.01 level (2-tailed)

TABLE II. CORRELATION ANALYSIS BETWEEN EXPERIENCE MEDIUM AND EXPERIENCE VALUE

\begin{tabular}{|l|l|l|l|}
\hline $\begin{array}{l}\text { Experience } \\
\text { Medium }\end{array}$ & $\begin{array}{l}\text { Functional } \\
\text { Value }\end{array}$ & $\begin{array}{l}\text { Emotional } \\
\text { Value }\end{array}$ & $\begin{array}{l}\text { Social } \\
\text { Value }\end{array}$ \\
\hline Environment & $0.556^{* *}$ & $0.477^{* *}$ & $0.417^{* *}$ \\
\hline Service & $0.593^{* *}$ & $0.522^{* *}$ & $0.538^{* *}$ \\
\hline$* * \mathrm{P}<0.01$
\end{tabular}

2) Correlation Analysis Between Eexperience Value and Loyalty

Loyalty is correlative to all the three dimensions of experience value. Correlation is significant at the 0.01 level (2tailed).

TABLE III. CORRELATION ANALYSIS BETWEEN EXPERIENCE VALUE AND LOYALTY

\begin{tabular}{|l|l|l|l|}
\hline & Functional Value & $\begin{array}{l}\text { Emotional } \\
\text { Value }\end{array}$ & Social Value \\
\hline Loyalty & $0.532^{* *}$ & $0.572^{* *}$ & $0.457 * *$ \\
\hline$* * \mathrm{P}<0.01$ & \multicolumn{2}{|l}{} \\
\hline
\end{tabular}

\section{Regression Analysis}

1) Regression Analysis between Experience Medium and Experience Value

a) Regression Analysis between Experience Medium and Functional Value 
By using multiple stepwise regression analysis, the regression results indicate that the $F$ value is 71.391 . The regression analysis between experience medium and functional value is significant and the significant level is 0.000. It indicates that the two variables (Environment and Service) reflect the change of functional value in the regression equation. From the above regression analysis, the impact of environment on emotional value is greater than that of service. Therefore, it leads to the standard regression equation below.

Functional Value $=0.407 \times$ Environment $+0.318 \times$ Service

b) Regression analysis between experience medium and emotional value

The $\mathrm{F}$ value is 33.574 for the regression analysis between experience medium and emotional value, which is significant and the significant level is 0.000 , so does a T-test. This indicates that regression coefficient is available to describe emotional value. And then it leads to the regression equation as following:

Emotional Value $=0.470 \times$ Environment $+0.166 \times$ Service

c) Regression analysis between experience medium and social value

The $\mathrm{F}$ value is 47.034 for the regression analysis between experience medium and social value, which is significant and the significant level is 0.000 . Therefore, it indicates that change of environment could reflect change of social value in the regression equation.

According to the result, the factor of service does not enter the regression model, so it leads to regression equation as following:

\section{Social Value $=0.627 \times$ Environment}

2) Regression analysis between experience value and loyalty

After the analysis below, $F$ value is 70.397 for the regression analysis between experience value and loyalty, which is significant and the significant level is 0.000 . Therefore, it indicates that change of the two variables (Emotional Value and Social Value) can reflect the change of loyalty in the regression equation.

The impact of emotional value on loyalty is greater than the factor of social value. So according to the analysis above, it achieves the standard regression equation as following:

\section{Loyalty $=0.414 \times$ Emotional Value $+0.337 \times$ Social Value}

\section{E. Hypothetical Verification}

From the analysis and discussions, the study assumed 9 situations, and there have been 7 hypothesizes empirically supported with 2 not supported. We can see that some variables have not been verified and we moderate the model according to the previous.

The results of the demographic characteristic variables' impact on other variables analysis and we use the one-way ANOVA to analyze the results. The results show: (1) unmarried consumers have a high perception in environment experience and social value than married. (2) Consumers below 20 years age old have the highest ranking on experience evaluation. And the reason is that these groups are to get a return on experience. (3) Consumers of different income per month have a significantly different evaluation on experience perception. The phenomena that consumers with higher monthly income have lower degree of recognition, indicates that they usually have higher requirement on overall environment of a coffee shop.

\section{DISCUSSION}

Based on the study of literature, we have conducted this research from the consumer experience. This study theoretically and empirically constructs the relationship model of experience medium, experiential value and loyalty. Then we put forward hypothesizes and the results are as follows: (1) Between Experiential Products and Experiential Value, the cafe shop environment has significantly positive effect on functional value, emotional value and social value. The personnel services has a significantly positive effect on functional value and emotional value. (2) Between Experiential Value and Consumer Loyalty, emotional value and social value have positive effect on consumer loyalty; and functional value doesn't work on consumer loyalty. (3) Different individual characteristics do not have significant differences on the consumer loyalty. Consumers of different marital status and age exist significant differences on cafe environment and social value. Consumers of different ages have significant differences on cafe environment, so does consumers of different income.

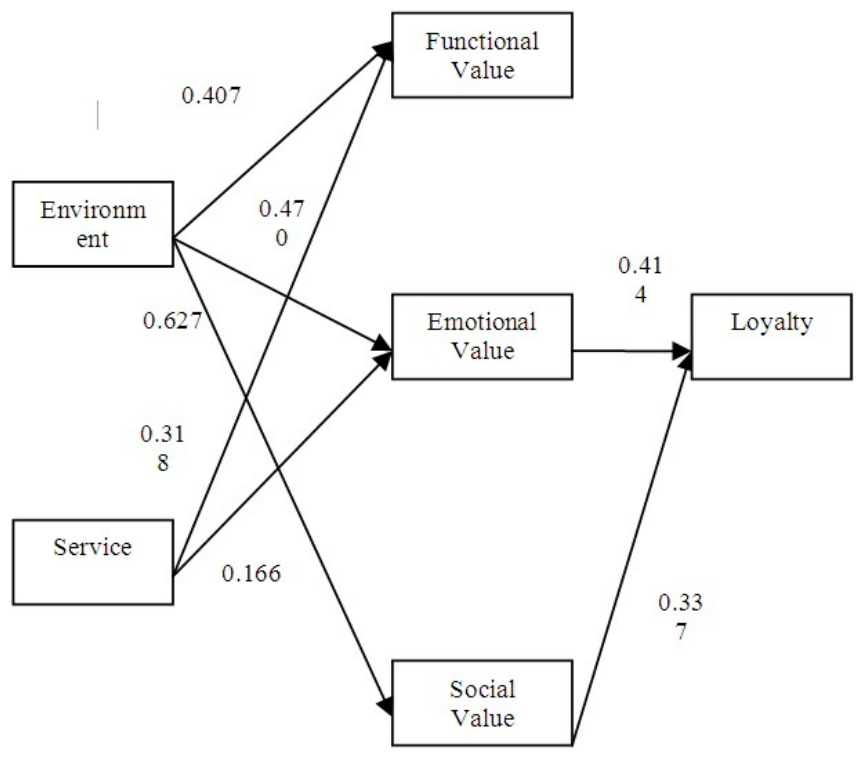

Figure2.The moderated theory model

Our findings contribute to research in several ways. By studying different types of consumers in the coffee chain, we find the main factors with an impact on the experiential value and loyalty. By reviewing experiential marketing and consumer loyalty theories, it has built an analytical framework between consumer relationship and loyalty, including the relevance of consumer experience and experiential value perception in 
consumer medium, and what are the main experiential value factors that impact on loyalty as well as the extent of the impact.

Our results must be viewed in light of the study's limitations. First, as we only select coffee chain as our sample and this may have a big difference with other food and beverage industry. Secondly, we only conduct this survey in Guangzhou and consumer preferences and experiences will be influenced by its economic strength and geographical factors to a large extent. So in future work, researchers should strive for a broader sample of China. Thirdly, there may be other factors besides environment and service as the main experience medium. Future studies may introduce other factors in the model.

\section{REFERENCES}

[1] Ardill, R. Brand Papers-Experience Economy: Getting organized [J]. Brand Strategy, 2006, 7(17):36

[2] Addis, M. \& Morris, B.H. On the Conceptual Link between Mass Customization and Experience Consumption: An Explosion of Subjectivity[J]. Journal of Consumer Behavior, 2001, 1(1):55-64

[3] Ardill, R. Brand Papers-Experience Economy: Getting organized [J]. Brand Strategy, 2006, 7(17):36

[4] Arnould, E.L. \& Price River Magic: Extraordinary Experience and the Extended Service Encounter[J]. Journal of Consumer Research, 1993, 20(6):24-45

[5] Baker, Julie, A.Parasuraman, Dhruv Grewal \& Glenn B. Voss. The influence of Multiple Store Environment Cues on Perceived
Merchandise Value and Patronage Intentions[J]. Journal of Marketing, 2002, 4(66):120-141

[6] Baker, Julie, Michael Levy \& Dhruv Grewal. An Experimental Approach to Making Retail Store Environmental Decisions[J]. Journal of Retailing,1992, 10(68):445-460

[7] Bennett, R., Hartel, C.E.J. \& Mccoll-Kennedy, J.R. Experience as A Moderator ofInvolvement and Satisfaction on Brand Loyalty in A Business-to-business Setting[J]. Industrial Marketing Management, 2005, 34:97-107

[8] Bernard, W. Attributional Thoughts about Consumer Behavior[J]. Journal of Consumer Research, 2000,27(3):382-387

[9] Blackwell, R.D.,Paul W.M., \& James F.E. consumer Behavior[J]. Harcount, Inc.,2001,9th

[10] Bitner, Mary Jo. Evaluating service encounters: The effects of physical surroundings and employee responses[J]. Journal of Marketing, 1990, 54(2):69-82

[11] Boulding,W., Kalra, A., Richard, S. \& Zeithaml, V.A. A dynamic process model of service quality: From expectation[J]. Journal of Marketing Research, 1993,1(30):7-27

[12] Burns, M.J. The consumer Perspective, Dissertation, Konxville [M].The University of Tenessee, 1993

[13] Carlos, J.F. Candido and D. Morris. The implementations of service quality gaps for strategy implementation[J]. Total Quality Management, 2001,12(7):825

[14] Cronin, J.J., Brady, M.K. \& Hult, T.G. Assessing the Effects of Quality, Value, and Consumer Satisfaction on Consumer Behavioral Intentions in Service Environments[J]. Journal of Retailing, 2000,2(76):193-218

[15] Deighton, John and Kent Grayson. Marketing and Seduction: Building Exchange relationships by Managing Social Consensus[J]. Journal of consumer Research, 1995, 21(3):660-676 